\title{
Informação em tempos de Covid-19 e patrimônio cultural de ciência e tecnologia: de onde viemos e para onde vamos
}

\author{
Information in Covid-19 times and cultural heritage of science and \\ technology: where we came from and where we are going
}

Victor Emmanuel T. M. Abalada ${ }^{a}$

Bruno Melo de Araújob

Marcus Granato ${ }^{\mathrm{a}}$ * (D)

Emanuela Sousa Ribeiro ${ }^{b}$ (D)

\begin{abstract}
RESUMO: O artigo propõe-se a discutir o papel do patrimônio cultural, em especial, daquele relacionado à Ciência e à Tecnologia, em tempos da pandemia COVID-19. A pesquisa realizada está no âmbito da Museologia e dos estudos sobre o patrimônio e caracteriza-se como uma investigação qualitativa, com o objetivo de ser reflexiva e descritiva, buscando retratar as relações entre a informação sobre a Covid-19 e o estado da arte sobre o Patrimônio Cultural de Ciência e Tecnologia (PCC\&T) nos dias atuais. Após discutir conceitos como Ciência, Informação, Poder, Patrimônio, dentre outros, parte-se para uma análise dos dados encontrados, de forma a mostrar como se interconectam, com o objetivo de caracterizar o PCC\&T como forma de articulação social que possibilita compreender o presente, a partir dos vestígios ainda existentes sobre o passado. Nesse contexto, segue-se a discussão sobre os efeitos da pandemia de COVID19, relacionando-a com casos específicos do PCC\&T selecionados (vacinas e respiradores), na intenção de clarificar como os usos, atuais e potenciais, do PCC\&T podem fornecer subsídios para decisões sanitárias, políticas, sociais, jurídicas e econômicas mais adequadas.
\end{abstract}

Palavras-chave: Patrimônio Cultural; COVID-19; Ciência e Tecnologia; Informação.

ABSTRACT: The article proposes to discuss the role of cultural heritage, especially that related to Science and Technology, in these times of the pandemic COVID-19. The research carried out is within the scope of Museology and studies on heritage and is characterized as a qualitative investigation, with the aim of being reflective and descriptive, seeking to portray the relationships between information about Covid-19 and the state of the art on the cultural heritage of Science and Technology (CHST) in the present day After discussing concepts such as Science, Information, Power, Heritage, among others, we proceed to an analysis of the data found, in order to show how they interconnect and aiming to characterize the CHST as a form of social articulation that makes it possible to understand the present, based on the vestiges that still exist about the past. In this context, the discussion on the effects of the pandemic of COVID-19 follows, relating to specific cases of the selected CHST (vaccines and respirators), in order to clarify how their current and potential uses can be the basis for health, political, social, legal and economic policies.

Keywords: Cultural Heritage; COVID-19; Science and Technology; Information.

\footnotetext{
a Museu de Astronomia e Ciências Afins, Rio de Janeiro, RJ, Brasil.

b Departamento de Antropologia e Museologia, Universidade Federal de Pernambuco, Recife, PE, Brasil.

*Correspondência para/Correspondence to: Marcus Granato. E-mail: marcus@mast.br.

Recebido em/Received: 15/08/2020; Aprovado em/Approved: 21/12/2020.
}

Artigo publicado em acesso aberto sob licença CC BY 4.0 Internacional (c) 


\title{
INTRODUÇÃO
}

Vivemos, nos últimos seis meses, imersos numa realidade que se restringe a um aspecto específico: a pandemia de coronavírus, COVID-19. Praticamente todos os meios de comunicação, formais e informais, debruçam-se sobre debates relacionados à pandemia, e a sociedade acompanha com ansiedade, temor e interesse o turbilhão de informações que se abate sobre nós. A qualidade e a intencionalidade dessas informações resultam em atitudes e efeitos diversificados, nem sempre auxiliando no combate à pandemia. Muitas questões surgem a partir dessa constatação, mas nos interessa especificamente discutir como o patrimônio cultural, em especial aquele relacionado à Ciência e Tecnologia (C\&T), pode(ria) auxiliar em uma melhor compreensão da pandemia que estamos vivenciando e, principalmente, na compreensão dos processos informacionais em curso.

Nesse contexto, incluem-se bens que se inserem no cotidiano de laboratórios de pesquisa de todas as áreas do conhecimento e contribuíram para o desenvolvimento da ciência e da tecnologia no país. Tais bens estão em universidades, escolas secundárias, centros de pesquisa, museus (quando já preservados) e, em sua maioria, são pouco conhecidos e valorados, o que gera vazios de informação. Segundo Granato e colaboradores:

\begin{abstract}
... os vazios documentais constituem-se em verdadeiros desafios para os historiadores e a sociedade em geral, no sentido de dificultarem a compreensão dos fatos e processos sociais, possibilitando maior incerteza sobre as narrativas construídas sobre nosso passado. Isto pode interferir diretamente com a memória e a noção de cidadania de cada um (Granato et al 2018, p.203).
\end{abstract}

Diversos estudos (Araújo, Granato 2017; Granato et al. 2014; Granato 2013; Lourenço, Wilson 2013; Granato, Lourenço 2010) vêm demonstrando que quase nada se preserva das materialidades que poderiam vir a constituir o Patrimônio Cultural de Ciência e Tecnologia (PCC\&T), mas, mesmo assim, neste momento crucial, torna-se possível visualizar sua inserção providencial para compreensão, especialmente, da Ciência como um dos processos legítimos de interpretação da realidade e dos cientistas em sua dimensão humana e laboral. Nosso recorte, como já mencionado, relaciona-se ao patrimônio cultural e, a partir dele, à possibilidade da compreensão de situações como a que estamos vivendo poderem ser interpretadas com as contribuições interdisciplinares ${ }^{1}$ mas, especialmente, com a contribuição das ciências humanas e sociais, que atualmente têm sido alijadas, a partir de discursos excludentes e retrógrados. Certamente há, de nossa parte e de todos que têm se dedicado a analisar seriamente os acontecimentos ainda em curso, o receio das conclusões apressadas e da falta de distanciamento, cronológico e emocional. Pela própria natureza contemporânea e polêmica do assunto, ativamente influindo na vida de todos, bem como pela escolha de uma abordagem menos usual dentro dos estudos que vêm explorando o tema, questões são levantadas acerca da influência de posições subjetivas dos autores.

Contudo, enquanto ciência social aplicada, a Museologia, disciplina que analisa as relações do homem com o real, vem enfrentando análises deste tipo, desde o seu

\footnotetext{
1 Segundo Pinheiro (2006 p. 111), a interdisciplinaridade é inerente às ciências humanas e sociais e pode ser definida como uma metodologia de pesquisa em que interagem, no mínimo, duas disciplinas, em perspectivas teóricas e/ou metodológicas.
} 
surgimento como campo do conhecimento autônomo², e, neste momento, mais do que nunca, se coloca como interlocutora das taxionomias (Bourdieu 2004a) vigentes na sociedade contemporânea. Até mesmo em campos do conhecimento epistemologicamente mais preocupados com as temporalidades, como a História, essas questões já vêm sendo abordadas e refutadas a partir de estudos da "história do tempo presente", que mostram como "o recuo temporal não conduz necessariamente a uma análise isenta de perspectiva, já que se pode analisar um objeto muito recuado no tempo a partir de diversos enfoques" (Fico 2012, p. 46).

A pesquisa realizada para elaboração deste artigo traz em sua base os fundamentos teóricos pertencentes à Museologia e aos estudos sobre o patrimônio, buscando o diálogo com conceitos da Ciência da Informação. Caracteriza-se como uma investigação qualitativa, com o objetivo de ser reflexiva e descritiva, buscando retratar as relações e os elementos selecionados sobre a realidade estudada. Utiliza como fontes principais as bibliográficas e aquelas consideradas primárias, como artefatos, legislações, documentos arquivísticos, entrevistas e mesmo os conteúdos publicados em jornais e revistas.

Assim, após a discussão de conceitos, parte-se para uma análise dos dados encontrados, de forma a mostrar como se interconectam, com o objetivo de caracterizar o PCC\&T como forma de articulação social que possibilita compreender o presente, a partir dos vestígios ainda existentes sobre o passado. Nesse contexto, segue-se a discussão sobre os efeitos da pandemia de COVID-19, relacionando-a com o PCC\&T, na intenção de clarificar como seus usos atuais e potenciais podem ser base para decisões sanitárias, políticas, sociais, jurídicas e econômicas mais adequadas.

\section{CIÊNCIA E PODER: DE ONDE VIEMOS E ONDE ESTAMOS}

O conceito de informação é essencial para definir a sociedade hodierna, no que tem sido chamado de Era da Informação e do Conhecimento. Esta perspectiva pressupõe um reposicionamento do conceito tradicional de informação - compreendida como forma de transmissão de conhecimento - para um olhar mais voltado a políticas e práticas da informação. Neste sentido, Capurro e Hjorland (2007) constroem um sólido debate acerca da própria necessidade de definição do conceito de informação no âmbito da Ciência da Informação, concluindo que mais importante do que definir a informação, é compreender epistemologicamente o porquê do seu uso em cada estudo.

Seguindo esta perspectiva é que adotamos uma definição abrangente de informação, ancorada nos mesmos autores - informação é aquilo que é informativo para uma determinada pessoa. O que é informativo depende das necessidades interpretativas e habilidades do indivíduo (embora estas sejam frequentemente compartilhadas com membros de uma mesma comunidade de discurso)" (Capurro e Hjorland 2007, pp.154-

\footnotetext{
${ }^{2}$ A Museologia é um campo recente do conhecimento com diferentes formas de abordagem da realidade. Mensch (1992) faz um resumo interessante das diversas vertentes de atuação da disciplina, que seriam: como ciência cuja finalidade é o estudo e a organização dos museus; como estudo de implementação e integração de certo conjunto de atividades, visando à preservação e ao uso da herança cultural, desdobrando a pesquisa em museus ou em qualquer instituição; como estudo dos objetos museológicos ou da musealidade como qualidade distintiva de museu; como estudo de uma relação específica entre homem e a realidade. Schaerer (1999, p.32) define a Museologia como "um campo de pesquisa definido de forma muito ampla e que inclui uma atitude específica do homem face a objetos (ou dos seus valores conceituais). Essa atitude inclui os procedimentos de conservação (musealização), de pesquisa e de comunicação (visualização). Por ter sido institucionalizado e analisado no museu, esse fenômeno tirou seu nome daí, o que muitas vezes induz mal-entendidos na medida que assimila a museologia como 'ciência do museu' unicamente".
} 
155) -, a fim de centrar nossa atenção na função social e interpretativa dos atuais sistemas de informação, focando na análise do processo social das relações entre ciência, PCC\&T e a COVID-19, no atual contexto informacional.

Devemos estar atentos ao redesenho das relações de poder e informação emanadas do campo científico, principalmente por estarmos em um contexto de surgimento e consumo de novas tecnologias informacionais. Atrelado à pandemia, descortina-se um cenário com excesso de informações: algumas de fontes confiáveis; outras, nem tanto, o que, muitas vezes, torna difícil a construção de uma ideia sobre o tema ou a tomada de uma decisão, especialmente quando aspectos políticos interferem sobremaneira no que se divulga. Nestas situações, tende-se a multiplicar informações falsas ou manipulá-las, com fins duvidosos. Os impactos destas ações têm sido nefastos, e o Brasil acumulou, até a presente data, mais de 3.000 .000 casos confirmados e mais de 100.000 óbitos. $^{3}$ Em grande medida, as falsas notícias têm cunho negacionista e contestam a gravidade da situação, a importância do isolamento e o papel da ciência, colocando em cheque informações idôneas, especialistas e processos científicos.

Certamente, não se trata de reificar o conhecimento científico como detentor da verdade e da hegemonia na apreensão da realidade social; tampouco, se trata de estabelecer uma dicotomia entre ciência e senso comum, em que a política tem trânsito intenso. As relações de poder estão centradas na validade das informações apresentadas por diferentes sujeitos e instituições, em termos dos embates vivenciados pelos atores tanto do campo da ciência quanto do campo político neoliberal.

Gostaríamos de operar a partir de uma ciência que se faz no constante diálogo com os saberes do senso comum, em uma perspectiva integradora de todas as áreas do conhecimento. Entretanto, o modelo de ciência predominante do século XIX até os dias atuais é

\begin{abstract}
... um modelo global de racionalidade científica que admite variedade interna, mas que se distingue e defende, por via de fronteiras ostensivas e ostensivamente policiadas, de duas formas de conhecimento não-científico (e, portanto, irracional) potencialmente perturbadoras e intrusas: o senso comum e as chamadas humanidades ou estudos humanísticos (em que se incluíram, entre outros, os estudos históricos, filológicos, jurídicos, literários, filosóficos e teológicos) (Santos 1988, p. 48).
\end{abstract}

Este modelo, baseado na exclusão e em uma racionalidade quase que totalitária - na medida em que desqualifica qualquer outra forma de conhecimento - é ainda vivenciado no âmago do próprio campo científico e, mais ainda, reconhecido socialmente por aqueles que estão à margem deste campo, que são, na realidade brasileira, a enorme maioria da população, cujo nível de escolarização formal não corresponde ao seu nível educacional.

Embora Santos (1988) tenha desenhado, em fins do século XX, um perfil do novo paradigma para a ciência pós-moderna, afirmando que esta chegaria a sensocomunizar-se na medida em que estabelecesse novas práticas epistêmicas, não podemos dizer que esta utopia já se realizou.

Em síntese, podemos dizer que o campo científico se estabeleceu e permanece calcado em distinções. Como aponta Bourdieu (2004b), o campo científico possui suas próprias

3 [Acesso em 11 agosto 2020]. Disponível em: https://covid.saude.gov.br. 
normas, práticas de validação, disputas intestinas e, como qualquer outro campo, é tão mais forte quanto mais puder fazer valer suas próprias práticas, competências e interesses, de maneira autônoma.

Para compreender a relação da sociedade brasileira com a ciência, atrelamos a perspectiva bourdiesiana, da autonomia do campo científico, ao seu enorme desconhecimento social no Brasil. Por exemplo, um dos elementos básicos necessários para a aquisição de capital científico, a titulação de doutor, atinge apenas 7,6 habitantes em cada 100.000 brasileiros, quantitativo que apenas chega a quase metade do encontrado nos países desenvolvidos com menor número de doutores. ${ }^{4}$ Com tão baixo nível de presença de pesquisadores ${ }^{5}$ no país, é difícil imaginar que a enorme maioria da sociedade sequer conheça, quanto mais compreenda, as práticas científicas e o funcionamento do campo.

Associando o hermetismo do campo científico à sua diminuta presença no Brasil e ao frequente distanciamento entre ciência e senso comum, construído desde o século XVIII no Ocidente, não é difícil compreender por que, mesmo diante de mais de 100.000 mortos, o país tem deslegitimado continuamente o conhecimento científico. Por fim, é importante lembrar que a maior parte deste conhecimento é produzida em universidades públicas, as quais, por décadas, foram espaços discriminatórios e muito raramente frequentados pelos menos privilegiados da população.

Políticas que procuraram alterar essa realidade, apesar de recentes, produziram resultados importantes. Segundo dados das Pesquisas Nacionais de Perfil Socioeconômico e Cultural de Graduandos das IFES (instituições federais de ensino), ${ }^{6}$ realizadas entre 1996 e 2018, houve uma alteração nos níveis de rendas familiares em percentuais, especialmente entre 2010 e 2014, quando a faixa até 1 salário mínimo cresceu de 10,1\% (2010) para 53,9\% (2014), mantendo-se nesse patamar até 2018. Em quinze anos (entre 2003 e 2018), diversas iniciativas do Estado contribuíram para elevar o número de estudantes pretos (as) e pardos (as) estudando nessas instituições de 160.527 para 613.826 , com variação de $282 \%$. No entanto, esses resultados são recentes, e já vêm sendo desarticulados nos últimos 2 anos, diminuindo seu impacto. Há que se ressaltar que pesquisas que produziram os dados aqui apresentados têm origem nas ciências humanas e sociais aplicadas, reforçando o papel destas áreas para a indução de políticas públicas que modifiquem quadros de desequilíbrio social.

Compreender o funcionamento do campo científico ainda implica lidar com problemas de outra natureza que atingem o Brasil: a grande dependência dos campos temporais e a fragilidade da infraestrutura da produção científica. Bourdieu (2004b) aponta dois tipos de capital existentes no âmbito do campo científico: uma atuação temporal/política e outra atuação "científica pura". A atuação temporal/política está vinculada à ocupação de cargos, à destinação de verbas e postos de trabalho em ministérios e universidades, por exemplo (Bourdieu 2004b). Trata-se, portanto, dos grupos que estão mais próximos da burocracia dita temporal, e quanto mais esta burocracia - que nem sempre reconhece as normas incorporadas pelo capital científico

\footnotetext{
4 [Acesso em 14 agosto 2020]. Disponível em: https://cartacampinas.com.br/2019/05/brasil-precisa-dobrar-numero-dedoutores-para-atingir-o-nivel-mais-baixo-dos-paises-desenvolvidos/.

5 Doutorado é um elemento de distinção em qualquer país do mundo; contudo, a desigualdade brasileira se faz sentir também no número daqueles que conseguem ser doutores.

${ }^{6}$ [Acesso em 13 agosto 2020]. Disponível em:

http://www.ufes.br/sites/default/files/anexo/v_pesquisa_do_perfil_dos_graduandos_16_de_maio.pdf.
} 
puro - está embaralhada no âmbito estrito do capital científico puro, menos autônomo ele é.

Novamente trazemos dados da realidade brasileira para apontar o quanto essas forças atuam em nossos tempos e interferem diretamente no campo científico e nos capitais por ele produzidos. A fragilidade das instituições que produzem ciência no Brasil é acentuada pela falta de políticas de Estado nas áreas relacionadas, que gera cortes na dotação orçamentária, em áreas que são estruturantes para o desenvolvimento da C\&T no país, como, por exemplo, em bolsas para pós-graduação e recursos para editais de projetos de pesquisa, e reforça as exclusões do campo científico e sua dependência da burocracia temporal.

A emergência sanitária promovida pela COVID-19 colocou em questão, entre seus múltiplos aspectos, a relevância das ciências humanas e sociais. Aos que acreditavam que deveríamos voltar os investimentos para as "ciências úteis", em viés tecnicista, a pandemia demonstra que a dissociação entre ciências hard e soft está ultrapassada. Para além disso, vem a frisar a necessidade de interlocução e cooperação entre diferentes profissionais e campos de conhecimento, especialmente quando se percebe que cabe às ciências soft identificar prioridades quanto às carências que afligem diferentes grupos sociais, para quais devem, prioritariamente, ser dirigidos os recursos públicos. A COVID-19 é um problema global que necessita de ações globais e integradas (Harari 2020). Para esse problema, no qual os verdadeiros antídotos que se impõem são a cooperação e a informação, não a segregação ou os nacionalismos.

Nesse sentido, cabe pautarmos a reflexão sobre processos de difusão e recriação de mensagens emanadas da "comunidade científica", ou seja, o modo como discursos e práticas se propagam entre diferentes grupos e categorias sociais. Em um país caracterizado por desigualdades, onde significativa parte da população não acessa serviços de saneamento básico e água encanada, qual a apreensão das comunidades aos apelos por isolamento social e cuidados mínimos de higiene corporal? O que significa "ficar em casa" ou "lavar as mãos regularmente" para trabalhadores ambulantes, moradores de rua ou presidiários? O que significa isolar os mais vulneráveis?

O esforço de congregar áreas do conhecimento com fins de lutar contra doenças e a desinformação propagada já teve êxitos em nossa história recente. Por exemplo, o surgimento da AIDS, na década de 1980, colocou em pauta a necessidade de construção de uma agenda interdisciplinar da ciência em busca de verbas para pesquisa, medicamentos, debates e acesso à informação. Esse processo se deu pelo entrelaçamento do campo científico com a política e resultou na integração entre reforma sanitária e reforma da medicina, que se pautou no princípio da integralidade da saúde calcado pelos conhecimentos provenientes de diversas disciplinas, mas, em especial, das ciências humanas e sociais. A partir desta perspectiva, a saúde descolouse do binômio com a doença e começou a ser encarada como conjunto de condições integrais e coletivas de existência influenciadas pelos contextos político, socioeconômico, cultural e ambiental.

O princípio mencionado está fundamentado na interdisciplinaridade e demanda estruturas permanentes no tempo, que possibilitem o desenvolvimento de pesquisas de longo prazo, com múltiplos participantes institucionais, e a transferência de conhecimento entre gerações de pesquisadores. Para a realidade brasileira, somente as estruturas do Estado possuem as características adequadas para tal. No entanto, mesmo aqui, se verificam mudanças radicais, com alterações no sistema de garantias para o funcionalismo público, tão demonizado, assim como a falta de concursos públicos para carreiras relacionadas à ciência e ao desenvolvimento tecnológico, que 
contribuem para a desestruturação das competências brasileiras, mesmo nas áreas mais maduras, por exemplo, na pesquisa sobre vacinas, tema que, com a pandemia, reassumiu visibilidade expressiva na sociedade.

A ciência pode até estar em evidência no contexto pandêmico; no entanto, os seus adversários utilizam ferramentas potentes e eficazes de manipulação que acabam por produzir descrédito, que só poderá ser revertido com o reposicionamento do campo científico e dos seus capitais, no sentido de produzir uma ciência aberta, como ferramenta de fortalecimento de redes de solidariedade e colaboração com informação qualificada, e disposta a sensocomunizar-se (Santos 1988).

Nesta perspectiva, é imprescindível analisar, ainda que brevemente, as relações entre ciência e política (no sentido tradicional do termo), pois esta é mais uma taxionomia presente na sociedade contemporânea e costuma implicar em graus cada vez maiores de manipulação de dados de origem científica. Ao tratar da ciência, Bourdieu é explícito ao afirmar que a objetividade do conhecimento científico é socialmente produzida e coletivamente legitimada e comunicada. Esta epistemologia implica, antes de tudo, um questionamento, uma autoconsciência, um autoposicionamento: “... objetivar o sujeito objetivante, objetivar o ponto de vista objetivante” (Bourdieu 2004a, p. 114). Isto significa perceber de onde e a partir de que cosmovisões falam os pesquisadores, de modo a superar pré-noções, enquanto se assume a consciência do lugar ocupado em termos de posição e condições sociais.

Se Bourdieu questiona os limites e os caminhos da objetividade científica, sua crítica à ciência reside na própria ontologia da questão proposta: o problema da formação do campo científico e seu discurso hermético em contrapartida à sua compreensão e à sua aceitação pela sociedade. A problemática apontada por Bourdieu se desdobra em dois tipos de atuação política: aquela formal, vinculada à ação administrativa do Estado, e outra vinculada às políticas informacionais, que se encontram mais claramente associadas ao PCC\&T, que será tratada no próximo item.

Do ponto de vista da atuação político-administrativa, a realidade mundial, bem como especificamente a brasileira, demonstraram, cotidianamente, os riscos do uso político da ciência, em especial ao adotar-se uma visão de ciência como conhecimento nítido, seguro, constante, que, ao contrário do que colocaria Bachelard (2006, pp. 170-173) como base do próprio espírito científico, não ousa criticar suas próprias asserções e acaba por naturalizar, seja seus métodos, seja seus resultados.

Para o caso brasileiro, um contexto bem estudado em diversas regiões do país é aquele vinculado às políticas de eugenia vivenciadas entre o final do século XIX e a primeira metade do XX. O uso dos estudos da Comissão de Melhoramentos da Cidade do Rio de Janeiro, de 1874, pelo prefeito Pereira Passos, no início do século XX, colocou em prática menos os dados científicos de novas teorias a respeito de contágio e prevenção de epidemias, com a já ideada ciência dos micróbios, do que recuperou o consenso dos miasmas, como forma de legitimar suas reformas urbanísticas, que se iniciaram em 1903, com a higienização e a reestruturação da cidade, promovendo, também, sob essa égide científica, um processo de "higienização social” (Furtado 2003, pp. 65-69).

A administração Pereira Passos, em sua virulência contra os hábitos das camadas mais populares, viria a desencadear ainda, em 1904, a Revolta da Vacina (Benchimol 2006, p. 264). Mesmo que se possa argumentar que a Revolta, por trás de sua superfície de reação popular à vacinação obrigatória trazia, para além de um ato dos cidadãos contra as arbitrariedades do governo, importantes ramificações políticas que buscavam mesmo a deposição do presidente Rodrigues Alves, não se pode deixar de observar aí um movimento que ilustra as possibilidades do que pode ocorrer, ao aliar-se ciência e 
poder, enquanto essa se afasta da informação e da sociedade. O resultado da Revolta foi a interrupção de um movimento ascendente de adesão à vacina, por causa de atitudes governamentais desastrosas, de modo que a população veio a sofrer tanto a repressão do movimento quanto a própria varíola (Benchimol 2006).

Como contraposição, poucos exemplos podem ser mais elucidativos da aplicação social do conhecimento científico do que a campanha de erradicação da varíola, recrudescida a partir do governo de Juscelino Kubitschek e que, de fato, se concretizou no período de 1966 a 1973. Embora em pleno período da ditadura militar, a campanha foi importante para um governo que necessitava de mecanismos de legitimação e, de maneira mais importante, para o surgimento de uma popular "cultura da imunização" no Brasil, com a população conquistando uma "cidadania biomédica" inclusiva, mesmo em uma sociedade desigual, com a oferta pública de amplo pacote de imunizantes e amplo alcance de campanhas de vacinação, situação sacramentada pela ideia da imunização como direito e da defesa constitucional do acesso à saúde que a redemocratização e a Constituição de 1988 trouxeram (Hochman 2001). Ainda que eventuais desconfianças - geralmente, oriundas da desinformação - possam abalar este quadro, como chegou a ocorrer, em 2009, na epidemia de gripe suína, isso não muda o fato de que, como coloca Hochman:

Vacinas, vacinadores e campanhas de vacinação fizeram parte do longo processo de estabelecimento da autoridade sanitária no Brasil. Territórios e populações foram incorporados ao Estado nacional a partir de artefatos como agulhas, lancetas, seringas, injetores e imunizantes (Hochman 2001, p. 384).

A materialidade aludida no discurso de Hochman já aponta para o papel do patrimônio cultural; porém, não se traduz em preocupação do campo para com a preservação de, ao menos, parte destes vestígios, nem com a inexistência de políticas claras de aquisição e descarte de acervos, tanto na legislação federal como nas principais instituições nacionais.

\section{CIÊNCIA, INFORMAÇÃO E PCC\&T}

A identidade do conhecimento científico contemporâneo coexiste com o patrimônio cultural, que se fundamenta nos valores atribuídos a objetos, edificações, tradições, enfim, a aspectos da condição humana, e busca representar a sociedade que com ele se relaciona.

Embora possamos associar, algumas vezes, o patrimônio cultural às experiências vividas no passado, a bibliografia sobre o tema é unânime em afirmar que o patrimônio se constrói no presente, através da atribuição de valores a bens materiais ou imateriais (Fonseca 2005), visando constituir identidades ou relações de poder que possam ser projetadas no futuro de qualquer agrupamento social. Discutir o patrimônio não é discutir o passado, mas interpretar processos de seleção e de afirmação de valores, no momento de seu reconhecimento como bem cultural. É também analisar a interação dos grupos sociais no tempo, suas diversas apropriações, reivindicações, e a construção de identidades. Essa noção passa por um longo e complexo processo, resultado de uma dialética entre a destruição/perda e a conservação, que possibilita atribuir valores aos bens culturais.

Como é de senso comum, o patrimônio tem relação com herança, com o que é repassado entre gerações, e, desta forma, compreende materialidades associadas a imaterialidades que são legadas, que documentam e simbolizam o que foi considerado, 
num determinado momento, como característico e representativo. A complexidade encontra-se, especialmente, naquilo que é selecionado para constituir essa herança, muitas vezes, sem o necessário respaldo social e cultural, propiciando desequilíbrios de leitura e compreensão ante desiguais condições e posições sociais, geopolíticas e geoeconômicas. O resultado percebe-se na contemporaneidade, através da interpretação que fazemos, a partir desses registros sobre realidades pretéritas, com vazios informacionais que impossibilitam conhecer e compreender dinâmicas de grupos marginalizados, por exemplo. Obviamente, não é possível guardar tudo, porém, é necessário ter políticas e critérios que possibilitem guardar algo, de modo a representar, democraticamente, diversos segmentos da sociedade, sua trajetória e sua cultura. No caso do PCC\&T, pesquisas mostram que faltam ambos no Brasil, levando ao descarte em massa dos vestígios materiais e à consequente perda de informação.

Percebe-se que, para além dos aspectos culturais que são inerentes ao conceito polissêmico de Patrimônio, identifica-se viés político significativo, no sentido de interferir na escrita da História e no investimento para a permanência de vestígios culturais, geralmente pertencentes às classes dominantes. O Patrimônio é, assim, uma forma de registro e tem potencial informacional.

A polissemia do termo se expressa de forma muito variada. Aqui nos interessam as variantes culturais - artístico, científico, arqueológico, tangível, intangível, industrial, histórico, etc. -, e cada termo adjetivante tipifica o patrimônio, assim como o qualifica. Historicamente, prevaleciam as variantes históricas e artísticas, mas, com o decorrer dos anos, outros tipos de patrimônio passaram a ser reconhecidos e preservados. Nesse contexto, surgem os denominados "novos patrimônios", que são reconhecidos a partir da segunda metade do século XX. Dentre eles, o patrimônio cultural de Ciência e Tecnologia (PCC\&T) apresenta relação estreita com o momento de pandemia e, por isso, é aqui problematizado.

O PCC\&T refere-se a uma tipologia de patrimônio que expressa retratos de diversos estágios das dinâmicas de produção de conhecimento científico e tecnológico, reconhecidos e valorados como bens culturais. A definição mais recente está registrada na Carta do Rio de Janeiro sobre PCC\&T, em que se lê:

... constitui-se do legado tangível e intangível relacionado ao conhecimento científico e tecnológico produzido pela humanidade, em todas as áreas do conhecimento, que faz referência às dinâmicas científicas, de desenvolvimento tecnológico e de ensino, e à memória e ação dos indivíduos em espaços de produção de conhecimento científico. Estes bens, em sua historicidade, podem se transformar e, de forma seletiva lhe são atribuídos valores, significados e sentidos, possibilitando sua emergência como bens de valor cultural (Carta 2017).

Como mencionado anteriormente, a maioria dos vestígios materiais relacionados ao PCC\&T já se perdeu, e isso significa perda de informação e constituição de narrativas históricas com vazios informacionais. Pesquisas que se debruçam sobre o tema (Araújo, Granato 2017; Granato et al. 2014; Granato 2013; Lourenço, Wilson 2013; Granato, Lourenço 2010) permitem afirmar que não há políticas de identificação e salvaguarda de bens culturais provenientes nas dinâmicas científicas e tecnológicas. Em grande medida, ambientes universitários, centros de pesquisa e laboratórios dialogam com a ideia do progresso científico e tendem a esquecer da ciência tal qual se faz, ou de uma ciência em ação, no seu cotidiano, com seus entraves, problemas, falhas e adaptações. Com uma perspectiva de conhecimento que olha para o futuro e para os avanços, acaba-se por produzir esquecimentos e silenciamentos. Lembrança e 
esquecimento são uma ambivalência própria dos patrimônios culturais, e não é diferente no âmbito do PCC\&T: as materialidades preservadas relacionam-se, em grande medida, com iniciativas particulares ou, em raros casos, com a atuação de instituições de longa data em nossa história, que buscam, com maior ou menor grau de sucesso, nas metodologias e práticas já estabelecidas, algumas alternativas para lidar com a realidade dos seus espaços, sem que se perceba, entretanto, uma ampla difusão deste pensamento e destas práticas.

Ainda assim, é possível encontrar, no país, coleções e conjuntos de objetos significativos para a história da ciência e tecnologia, como exemplifica, na área de saúde, o acervo da Casa de Oswaldo Cruz, no Rio de Janeiro. Trata-se de cerca de 2000 peças coletadas desde a gestão de Oswaldo Cruz, iniciada em 1902,7 destacando-se equipamentos de laboratório, materiais utilizados na produção de medicamentos e vacinas, instrumentos médicos, mobiliário, indumentária, objetos pessoais de cientistas etc. Há também acervos arquivístico e arquitetônico muito relevantes, que documentam cerca de 100 anos de atividades de pesquisa e desenvolvimento tecnológico, em especial, na área de vacinas e saúde coletiva.

Pensando o tempo presente, seria muito importante, em paralelo ao desenvolvimento de procedimentos e produtos para o combate à COVID-19, proceder ao registro e à coleta de testemunhos materiais que permitissem, futuramente, conhecer as dinâmicas e os processos de desenvolvimento de vacinas, procedimentos médicos que estão ocorrendo no presente. A partir de critérios pré-estabelecidos, seria possível, inclusive, caracterizar os atores envolvidos, os erros e os acertos, a não linearidade característica da pesquisa acadêmica, dentre outros aspectos particulares do campo científico. Assim, o patrimônio poderia, nesse caso, caracterizar as configurações do campo científico no contexto da pandemia.

Um caminho possível para a sistematização de uma política de incorporação de acervos poderia ser realizado a partir da observação dos contextos dos objetos. Um primeiro contexto está relacionado ao uso dos objetos, na relação estabelecida entre homens e outros objetos. Em sua vida funcional, o objeto transita por espaços e pode ser utilizado de diferentes formas, que podem não estar associadas ao seu uso original. O segundo contexto relaciona-se ao momento de inutilização dos objetos. Quando deixam de ter uso, estes podem ser encaminhados a um depósito, onde podem permanecer por algum tempo ou, simplesmente, ser jogados no lixo, o que ocorre com maior frequência. Por último, o contexto da sua preservação, no qual se promove o registro das suas etapas anteriores e se busca garantir as condições mínimas para sua proteção. Com essa compreensão, seria possível desenvolver uma ação coordenada sobre a realidade que se baseia na coleta ativa, voluntária e não passiva, como a simples aceitação de doações de objetos antigos. Os critérios adotados nesse processo visam garantir a integridade informacional e material dos objetos e pressupõem que nem tudo pode ser preservado, haja vista que se trata de um processo de escolhas.

Bourdieu (2004b) desvela uma aporia, ao mostrar que a autonomia do campo científico, defendida como a exclusão da interferência de interesses externos, é um ideal que deve comandar uma ética e uma política da ciência, para que, de fato, esta possa se configurar e atuar como campo relativamente autônomo, dependendo, para obter tal autonomia, tanto do grau de sua necessidade de recursos financeiros quanto do capital científico acumulado que exige para ser acessado. Entretanto, isto significa

7 [Acesso em 14 agosto 2020]. Disponível em: http://www.coc.fiocruz.br/index.php/pt/objetos-pessoais-e-de-trabalhode-oswaldo-cruz\#.U3n4eChwWRg. 
que a autonomia de um campo leva, também, à construção de uma forma específica de comunicação, acessível apenas aos detentores de certo capital linguístico e/ou cultural (Bourdieu 2007); de uma postura linguística que é a própria forma incorporada do sistema de princípios de visão e de divisão constitutivos do campo, e que, se o legitimam, dificultam ou impedem a compreensão dos "profanos" (Bourdieu 2007, p. 226).

Neste contexto, há de se refletir sobre a comunicação científica: como é feita e a quem se endereça. Tradicionalmente, a comunicação científica ${ }^{8}$ é vista como um fenômeno multifacetado, que, envolvendo diferentes atores, utiliza variados canais de comunicação e formatos, dividindo-se entre a disseminação e a divulgação científica (Oliveira 2018, p. 102). Se a disseminação seria a fala aos pares, aos especialistas de determinada área, através de veículos específicos do campo, como revistas e eventos acadêmicos (Bueno 2002), a divulgação cumpriria a função de democratizar o acesso ao conhecimento científico ao público leigo, por meio de "diferentes mídias massivas e espaços de compartilhamento em mídias sociais por diferentes atores sociais" (Oliveira 2018, p. 102). Entretanto, ao tentar traduzir a linguagem específica do campo científico, tornando-a mais acessível a não iniciados, a divulgação, ou vulgarização, científica é comumente acusada de trair o conteúdo da mensagem em sua simplificação, ou pior, de divulgar sua própria visão da ciência, em vez dos conteúdos desejados. Sob esta ótica, seriam difundidos não a compreensão da ciência e o seu método, mas os resultados e as palavras-chave destituídas de seu significado, de modo que "o público da vulgarização científica não aprende a conhecer a ciência e a tecnologia, mas sim a reconhecê-la por intermédio de um sistema de ícones e símbolos (nomes de laboratórios, terminologia, gráficos, aparelhos etc.)" (Ramos 1994, p. 344).

Segundo Oliveira (2018), a comunicação científica vem sendo afetada pelo processo cultural entendido como midiatização da ciência, no qual o ensino e a pesquisa tornamse cada vez mais digitais e/ou virtuais. Porém, este processo não fica restrito a um espaço "institucional", mas, através de novas tecnologias de comunicação e informação, acaba por adentrar espaços como as mídias sociais. Embora os próprios pesquisadores busquem manter-se cientes dos diversos públicos e do tipo de linguagem a adotar em cada espaço presente, questões como performance, visibilidade e facilitação do acesso tornam-se importantes para a prestação de contas à sociedade e aos órgãos de fomento, com pressão destes, por vezes, para que os pesquisadores busquem explorar redes sociais e mídias populares.

Esse cenário se torna irônico, pois, na medida em que o acesso ao conhecimento científico nunca foi tão fácil, vê-se a proliferação de tratamentos desacreditados pela ciência, atrelados à incompreensão do próprio discurso científico e à desvalorização da ciência, especialmente a produzida nas humanidades, mesmo como política governamental.

No entanto, é na relação entre diferentes áreas do conhecimento, das simplesmente desacreditadas às encaradas como inúteis, de acordo com uma visão pseudoutilitarista e imediatista do que seria o conhecimento científico, que reside a chave para a

\footnotetext{
${ }^{8}$ Como o artigo não visa analisar precisamente a questão da comunicação científica em si, mas apenas utilizá-la para compreender o papel da ciência e sua relação com o patrimônio cultural no mundo contemporâneo, uma maior discussão sobre o conceito não será feita. Porém, frisamos que o conceito vem sendo reinterpretado através do tempo e apresenta particularidades em cada área do conhecimento (Silva, Tavares, Pereira 2010). Apontamos também que, na contemporaneidade, sua discussão pode ser complexificada ao articulá-lo a outras questões que rondam a discussão proposta, como ciência cidadã e ciência aberta, mas que, devido ao foco e espaço limitado do artigo, tal discussão não pode ser realizada sem acarretar o alargamento do escopo observado e uma discussão teórica mais profunda cuja natureza estaria deslocada neste trabalho tal qual se propõe.
} 
construção de um conhecimento e um futuro para além da pandemia. Os números de infectados e óbitos não devem ser encarados como causalidades necessárias ou vítimas sacrificiais para que a sociedade se mantenha estruturada e funcional. Apenas com base no conhecimento científico, produzido de forma autônoma e contínua, será possível reverter essa e outras crises sanitárias. Assim, é necessário frisar o quanto as pesquisas nessa área são dependentes, também, do PCC\&T.

O patrimônio genético, que se insere no PCC\&T e, ao contrário da categoria maior que o compõe, tem legislação própria regulamentando sua proteção e seu acesso (Brasil 2015), em parte, pelos interesses econômicos que atrai, é peça fundamental para pesquisas na produção de vacinas. Constitui-se do conjunto de informações genéticas de espécies vegetais, animais, microbianas ou de outra natureza, incluindo substâncias oriundas do metabolismo desses seres vivos, e a lei busca regulamentar o uso destas informações, bem como o dos conhecimentos tradicionais associados, pensando na divisão dos benefícios provenientes da exploração econômica de produto acabado ou do material reprodutivo desenvolvido a partir do acesso ao patrimônio.

Sua importância, neste momento, para a obtenção de resultados futuros, pode ser mensurada pelo fato de, ainda que de forma destoante em relação à sua ação geral no enfrentamento da pandemia, no Brasil, os ministérios da Saúde e do Meio Ambiente terem emitido, em abril, portaria conjunta que liberava o cadastramento, no Sistema Nacional de Gestão do Patrimônio Genético e do Conhecimento Tradicional Associado (SisGen), de remessas de amostras de patrimônio genético utilizadas para pesquisa e desenvolvimento tecnológico, vinculadas à situação epidemiológica (Brasil 2020). Esta situação demonstra uma rara oportunidade para promover a adoção de práticas da ciência aberta e cidadã e o incentivo ao compartilhamento e abertura de dados. ${ }^{9}$

Já em março de 2020, o jornal Le Figaro noticiou a existência de, então, cerca de 30 projetos de vacinas contra o coronavírus, lançados por startups, laboratórios farmacêuticos e centros de pesquisa. Além de frisar as questões do complicado e demorado caminho para a aprovação e a produção da vacina, de acordo com os rígidos critérios do método científico, o jornal apontava que, em um dos estudos, nos EUA, ao invés de utilizar-se o vírus inativo, buscava-se utilizar um pedaço do patrimônio genético do novo coronavírus em reconstituição sintética, para fazer com que o organismo produzisse uma das proteínas deste, de modo que o paciente possa desenvolver uma resistência específica para neutralizar esta proteína. ${ }^{10}$

Entretanto, pode-se problematizar que, entre a descoberta de uma vacina eficaz e sua produção e disponibilidade global, há um abismo. A própria pressão pela produção de uma vacina em tempo recorde, disponível até o final de 2020, pode não parecer uma ideia tão boa, sob certa luz, com a pressão política podendo levar à simplificação dos testes e ao afrouxamento do rigor científico, de modo a produzir uma vacina cara, pouco segura ou eficaz, que venha a minar ainda mais a confiança na ciência e nas

\footnotetext{
9 Estudos relacionados a este patrimônio já ganharam alguns capítulos no Brasil. A análise das condições de preservação da coleção de Fungos Filamentosos da Fundação Oswaldo Cruz - FIOCRUZ, assim como as possibilidades de sua divulgação (Camara, 2008) servem como ilustração da exploração desta temática. Apontamos ainda, em escala internacional, experiências bem sucedidas no American Museum of Natural History e National Museum of Natural History, que desenvolvem pesquisas relacionadas ao Patrimônio Genético, focando em estratégias de conservação de espécies ameaçadas. [Acesso em 28 julho 2020]. Disponível em: https://www.amnh.org/research/invertebratezoology/staff/research-associates/sergios-orestis-kolokotronis/evolutionary-genetics-software.

${ }^{10}$ [Acesso em 28 julho 2020]. Disponível em: https://www.rfi.fr/br/fran\%C3\%A7a/20200319-mundo-tem-30-projetos-devacina-contra-o-coronav\%C3\%ADrus.
} 
vacinas no mundo de hoje. ${ }^{11}$ Ainda assim, apesar de falas como a do governo chinês, de que uma eventual vacina chinesa viria a ser "bem público mundial", ${ }^{12}$ atitudes como a dos EUA, que, em julho, compraram todas as vacinas (ainda em teste) capazes de ser produzidas até o final do ano pelas farmacêuticas Pfizer e BioNTech, ${ }^{13}$ mostram que, em nível global, a crise pode estar ainda longe de ser resolvida. E mais: que a posição de um Brasil que, economicamente fragilizado, se demonstra pouco hábil na política internacional, pode não ser das mais privilegiadas na fila de espera dessa vacina.

De qualquer forma, se, assim, se percebe que o patrimônio associado às áreas das ciências da saúde e das ciências biológicas já demonstra, no caso explorado, uma funcionalidade inequívoca aos olhos da sociedade em geral (muito embora não se busque fazer, na mídia, tão clara associação), o papel das ciências humanas permanece mais obscuro ao olhar leigo. No entanto, ele é facilmente percebido na seleção, na preservação, na construção e na interpretação do acervo patrimonial/documental que é gerado pelas pesquisas, pois, seguindo o enfoque na saúde, cada doença tem a particularidade de seu contexto histórico, de sua disseminação, do desenvolvimento de técnicas e tecnologias de combate, que somente é compreendida na interseção das áreas de saber. Estudar o que ocorre e/ou o que ocorreu e as possíveis contribuições do patrimônio, tanto no efetivo auxílio de superação da crise quanto na escrita de sua história, é entender as estruturas, tanto sociais, econômicas e políticas quanto materiais, que são produzidas e reproduzidas pela humanidade.

Tal situação remete, inclusive, ao risco dessas informações, hoje, estarem, em muitos casos, em suportes digitais e virtuais, correndo o risco da obsolescência de hardware, software e formatos, bem como da perda da informação em atualizações de páginas na web, com quebras de links e afins, e a conseguinte necessidade de se preservar, quando existente e possível, a materialidade e a informação para os estudos de amanhã.

Ao se pensar no patrimônio e na necessidade de preservação da sua materialidade, seja no caso do combate ao COVID-19, seja como um meio de pensar o que significa selecionar e preservar para o futuro, um bom exemplo da atualidade e relevância do PCC\&T pode ser evidenciado pela urgência de respiradores. Em meio aos primeiros esforços de produção deste equipamento, uma das ideias foi revisitar o minirrespirador Takaoka 600, uma invenção brasileira da década de 1950, que, pelos idos de 1980, passou a ser substituído por equipamentos mais modernos, importados. Toda experiência de pesquisa e produção do equipamento estava dispersa, sem nenhum tipo de registro institucional; porém, o apego a um equipamento que funcionava tão bem e estivera, durante tanto tempo, na rotina dos profissionais, levou alguns destes a guardarem consigo o aparelho, quando ele entrou em desuso e passou a ser descartado. Procurou-se fazer a engenharia reversa desses equipamentos para a sua replicação em impressoras 3D, mas, de maneira interessante, para conseguir realizar tal feito, foi necessário recorrer a coleções particulares de médicos e da Universidade Federal de São Paulo (UNIFESP). ${ }^{14}$ Este exemplo chama atenção para a

\footnotetext{
${ }^{11}$ [Acesso em 28 julho 2020]. Disponível em: https://www.thenation.com/article/society/vaccine-coronavirus-octobersurprise/.

12 [Acesso em 28 julho 2020]. Disponível em: https://noticias.uol.com.br/ultimas-noticias/afp/2020/05/18/eventualvacina-chinesa-contra-o-coronavirus-sera-bem-publico-mundial.htm.

${ }^{13}$ [Acesso em 28 julho 2020]. Disponível em: https://noticias.uol.com.br/saude/ultimas-noticias/estado/2020/07/22/euacompram-todas-as-vacinas-contra-covid-19-da-pfizer-e-biontech-em-2020.htm.

14 [Acesso em 30 julho 2020]. Disponível em: https:/www1.folha.uol.com.br/cotidiano/2020/04/contra-o-coronavirusgrupo-resgata-respirador-inventado-nos-anos-1950-no-brasil.shtml
} 
questão da invisibilidade dos objetos científicos não musealizados e como sua eventual preservação está ainda mais associada a atitudes de cunho pessoal do que a uma política institucional.

O exemplo das vacinas e, especialmente, o do respirador Takaoka 600, evidenciam a dificuldade de se garantir o mínimo de registro da produção do conhecimento científico e tecnológico. Não pretendemos, com essa argumentação, defender uma total preservação das materialidades provenientes dessas dinâmicas, mas evidenciar que ferramentas e iniciativas já construídas podem contribuir para a preservação de elementos significativos.

Destacamos, ainda, a inexistência de, pelo menos, um museu nacional de grande porte que preserve acervos dessa natureza e possa atuar como promotor e articulador na construção de uma política nacional com práticas de aquisição e descarte de acervos, ou seja, como formador de coleções. Não se trata de algo novo que pudesse ser um divisor de águas ou um novo paradigma para a preservação do PCC\&T. Iniciativas desse calibre já são desenvolvidas há longa data, por instituições como Science Museum (Londres), Deutsches Museum (Munique) e o Museum of Science and Innovation (Ontario).

Com este quadro, é apenas de se torcer que uma conscientização maior leve a um futuro diferente o ventilador pulmonar de baixo custo desenvolvido na USP, denominado Inspire que foi registrado com uma licença open source. ${ }^{15}$ Além de representar ações de desenvolvimento científico e tecnológico no Brasil, construídas durante a pandemia, apontam para uma maior consciência da preservação de sua materialidade para o futuro, e demonstram, também, um passo em prol de uma ciência colaborativa, aberta e cidadã, que se faz imprescindível para a preservação do PCC\&T.

\section{CONSIDERAÇÕES FINAIS}

Propôs-se aqui abordar os contextos complexos, dos presentes e dos passados recentes, relacionados a uma epidemia que assume contornos mundiais e que interfere, de forma determinante, na vida humana, gerando imagens de cidades inteiras vazias, centros de turismo mundial à deriva, imensa quantidade de desempregados e de óbitos. Diante deste cenário caótico e incerto, buscar discutir a importância do patrimônio cultural pode parecer um pouco deslocado ou desconectado da realidade. Contudo, a complexidade das relações sociais na contemporaneidade nos permite articular a dimensão do patrimônio cultural com as demandas impostas pela pandemia do Covid-19 que vêm impactando nossas formas de expressão, saberes, fazeres e sociabilidades.

De forma mais enfática, o patrimônio cultural de ciência e tecnologia pode ocupar lugar central neste debate, tendo em vista os crescentes questionamentos dirigidos à ciência e às suas práticas e, ao mesmo tempo, a necessidade de comunicar à sociedade as formas de produção científica, suas conquistas, seus limites e até mesmo os seus fracassos. Dessa forma, essa categoria patrimonial pode proporcionar acesso à informação qualificada e confiável, contribuindo para a construção de uma ciência aberta, dialógica e acessível aos diferentes grupos sociais.

\footnotetext{
15 [Acesso em 30 julho 2020]. Disponível em: https://jornal.usp.br/institucional/usp-e-marinha-do-brasil-se-preparampara-produzir-ventiladores-pulmonares/.
} 
Não se pretende exercer a futurologia. O conhecimento obtido tanto em relação ao PCC\&T quanto à atual conjuntura e o processo histórico permitem fazer observações acerca dos usos do patrimônio no futuro próximo, os significados que podem vir a ser atribuídos e o papel que o patrimônio pode representar no combate à COVID-19 e a outras tantas enfermidades, alterações no meio ambiente e quaisquer outros problemas sociais.

É deste modo que se levanta a preocupação, com base no apresentado, de que não há movimento organizado, com sustentáculo político e cultural, que permita a salvaguarda de bens de importância para a C\&T, com vistas ao futuro. Neste momento, inúmeros itens que poderiam, no futuro, constituir fontes para a construção de narrativas sobre o presente que vivemos, estão sendo descartados ou ignorados em diversos espaços de Ciência. A compreensão das gerações futuras sobre o nosso tempo presente e a forma como construímos a realidade vindoura certamente estará relacionada à atuação de identificação dos bens constituintes do patrimônio cultural, que desejamos consciente, fundamentada, organizada.

Em todo caso, o que fica evidente é a importância do tripé aqui abordado: patrimônio, ciência e informação. Estes elementos se mostram fundamentais para a saída desta crise e devem ser levados em conta, da mesma maneira, em possíveis crises futuras, sejam pandêmicas, climáticas ou ambientais, dadas como possibilidades por especialistas. Da mesma forma que o patrimônio já protegido, estudado e divulgado tem sua utilidade hoje, há a necessidade de se pensar na seleção e na conservação do patrimônio produzido para o amanhã.

\section{REFERÊNCIAS}

ARAÚJO, Bruno Melo de; GRANATO, Marcus. Entre o esquecer e o preservar: a musealização do patrimônio cultural de Ciência e Tecnologia. In: GRANATO, Marcus; RIBEIRO, Emanuela Sousa; ARAUJO, Bruno Melo de (Orgs.). Cadernos do patrimônio da Ciência e Tecnologia: instituições, trajetórias e valores. Rio de Janeiro: MAST, 2017. p. 231-254.

BACHELARD, Gaston. A epistemologia. Lisboa: Edições 70, 2006.

BENCHIMOL, Jaime. Reforma urbana e Revolta da vacina na cidade do Rio de Janeiro. In: FERREIRA, Jorge; DELGADO, Lucila de Almeida Neves (Orgs.). O Brasil republicano: da Proclamação da República à Revolução de 1930. Rio de Janeiro: Civilização Brasileira, 2006. p. 231-286.

BOURDIEU, Pierre. Coisas ditas. São Paulo: Brasiliense, 2004(a).

BOURDIEU, Pierre. Os usos sociais da ciência: por uma sociologia clínica do campo científico. São Paulo: Editora UNESP, 2004 (b).

BOURDIEU, Pierre. O poder simbólico. Rio de Janeiro: Bertrand Brasil, 2007.

BRASIL. Lei n ${ }^{13.123}$, de 20 de maio de 2015. Diário Oficial da União, Seção 1, 20 maio 2015. Disponível em: http://www.planalto.gov.br/ccivil_03/_At020152018/2015/Lei/L13123.htm. Acesso em: 14 ago. 2020.

BRASIL. Portaria interministerial $n^{\circ} 155$, de 3 de abril de 2020. Diário Oficial da União, 06 abr. 2020. Disponível em: 
http://pesquisa.in.gov.br/imprensa/jsp/visualiza/index.jsp?data=06/04/2020\&jornal=51 5\&pagina=74\&totalArquivos=177. Acesso em: 14 ago. 2020.

BUENO, Wilson da Costa. Jornalismo científico como resgate da cidadania. In: Massarani Luisa; MOREIRA, Ildeu de Castro; BRITO, Fatima (Orgs.). Ciência e Público: caminhos da divulgação científica no Brasil. Rio de Janeiro: Ed. Casa da Ciência, UFRJ, 2002.

CAMARA, Roberta Nobre da. A patrimonialização de material genético brasileiro: o estudo de caso coleção de fungos filamentosos do Instituto Oswaldo Cruz. 2008. Dissertação (Mestrado em Museologia e Patrimônio) - UNIRIO/MAST, 2008.

CAPURRO, R.; HJORLAND, B. O conceito de informação. Perspectivas em Ciência da Informação, v. 12, n. 1, p. 148-207, jan./abr. 2007. Disponível em:

http://portaldeperiodicos.eci.ufmg.br/index.php/pci/article/view/54. Acesso em: 25 jun. 2016.

CARTA do Rio de Janeiro. 2017. Disponível em: http://www.mast.br/images/pdf/Cartado-Rio-de-Janeiro-sobre-Patrimnio-Cultural-da-Cincia-e-Tecnologia.pdf. Acesso em: 14 ago. 2020.

FICO, Carlos. História do tempo presente, eventos traumáticos e documentos sensíveis: o caso brasileiro. Varia Historia, v. 28, n. 47, p.43-59, jan./jun. 2012.

Disponível em: https://www.scielo.br/pdf/vh/v28n47/03.pdf._Acesso em: 13 ago. 2020.

FURTADO, Janaína Lacerda. Dois lados da moeda: a Comissão de Melhoramentos da cidade do Rio de Janeiro e o discurso de higiene e saneamento no século XIX. 2003. Dissertação (Mestrado em História) - UERJ, 2003.

GRANATO, Marcus; MAIA, Elias da Silva; SANTOS, Fernanda Pires. Valorização do patrimônio científico e tecnológico brasileiro: descobrindo conjuntos de objetos de C\&T pelo Brasil. Anais do Museu Paulista, v. 22, p. 11-34, 2012.

GRANATO, Marcus; LOURENÇO, Marta Catarino. Patrimônio científico do Brasil e de Portugal: uma introdução. In: GRANATO, Marcus; LOURENÇO, Marta C. (orgs.). Coleções científicas luso-brasileiras: patrimônio a ser descoberto. Rio de Janeiro: MAST, 2010. p. 7-14.

GRANATO, Marcus. Scientific heritage in Brazil. Studies in History and Philosophy of Science, v. 44, p. 690-699, 2013.

HARARI, Yuval Noah. Na batalha contra o coronavírus, faltam líderes à humanidade. São Paulo: Companhia das Letras, 2020.

HOCHMAN, Gilberto. Vacinação, varíola e uma cultura da imunização no Brasil. Ciência \& Saúde Coletiva, v. 16, n. 2, p. 375-386, 2011. Disponível em: https://www.scielo.br/pdf/csc/v16n2/v16n2a02.pdf. Acesso em: 05 ago. 2020.

MENSCH, Peter Van. The object as data carrier: towards a methodology of museology. Tese (Doutorado em Museologia) - University of Zagreb, Croácia, 1992. 
OLIVEIRA, Thaiane Moreira de. Midiatização da ciência: reconfiguração do paradigma da comunicação científica e do trabalho acadêmico na era digital. MATRIZes, v.12, n. 3, p. 101-126, 2018.

PINHEIRO, Lena Vania Ribeiro. Ciência da Informação: desdobramentos disciplinares, interdisciplinares e transdisciplinares. In: GONZÁLES DE GÓMEZ, Maria Nélida; DILL ORICO, Evelyn Goyannes (orgs.). Políticas de memória e informação. Natal, RN:

EDUFRN, 2006. p. 111-142.

RAMOS, Marcos Gonçalves, Modelos de comunicação e divulgação científicas: uma revisão de perspectivas. Ciência da Informação, Brasília, v. 23, n. 3, p. 340-348, set./dez. 1994.

SANTOS, Boaventura de Sousa. Um discurso sobre as ciências na transição para uma ciência pós-moderna. Estudos Avançados, v. 2, n. 2, p. 46-71, 1988. Disponível em: http://www.scielo.br/scielo.php?script=sci_arttext\&pid=S010340141988000200007\&lng=en\&nrm=iso. Acesso em: 13 ago. 2020.

SCHÄERER, Martin R. La relation homme-object exposée: theorie et pratique d'une experience museologique. Publics et Musées, n. 15, p. 31-43, 1999.

SILVA, Edna Lucia; TAVARES, Aureliana Lopes de Lacerda; PEREIRA, José Paulo Speck. O estado da arte da pesquisa sobre comunicação científica (1996-2006) realizada no Brasil no âmbito da Ciência da Informação. Transinformação, v. 22, n. 3, p. 207-223, 2010. Disponível em: https://doi.org/10.1590/S0103-37862010000300002. Acesso em: 13 ago. 2020. 